\title{
Humanization as a Sociocultural Component of the Higher Education Quality
}

\author{
U.F. Sabirova, S.V. Gusenina, M.V. Sukhomlinova, V.I. Safyanov
}

\begin{abstract}
The third-generation universities are the multicultural organizations with a wide and diverse staff and students. In this regard they are close to medieval universities."

"Trying to find a way out of this situation universities are forced to experiment offering specialized programs to the best and brightest students thereby returning scientifically oriented education to the ideals of the Renaissance and Enlightenment. This can be seen as the sixth driving force behind change."

Johan Wissemah. "The Third Generation University" [3]

Introduction. In recent years the sociocultural trends of the modern educational system undergone significant transformations, thus making the question of studying them relevant. The concept of "humanity" is interpreted today in meaning close to the category of "personality", the quality of the life and the benefits which are becoming the main criteria for evaluating the activities of social institutions. The purpose of the article is a practical definition of the semantic and qualitative content of the concept of "humanization of the modern higher education" in accordance with the educational standards of the third generation.
\end{abstract}

Materials and methods. The methodological base included the systemic, synergetic, communicative, personal activity approaches as well as general theoretical methods (analysis, synthesis, comparison, generalization studies of sociological and social science literature); comparative analysis; empirical methods (observation, conversation, questionnaire, analysis of the results of the survey).

Results. It was established that "humanity" as a competence can be attributed to the motivational resources of the personality. A number of scientifically correct sociological parameters, characteristics, descriptors and indicators has been formed in accordance with the third generation Russian Federation the State Educational Standards (FSES). This allows them to be distinguished using the method of the "social portrait" and to characterize the conditional level of the competence "humaneness" formed among university graduates according to the universal scale of the competencies formation, approved by these standards ("high" - "satisfactory" - "good").

The analysis of the experimental work data revealed a "good" level of the formed conditional competence - "a person humanity" among the respondents - the University graduates in the Tambov region, Russia. Moreover the competency formation is considered by this study's authors as a criteria not for the person assessing itself, but the effectiveness and quality of the modern higher education.

Discussion and conclusions. The results and conclusions of the author's empirical research can serve as:

Revised Manuscript Received on 14, October 2019.

U.F. Sabirova, Department of Sociology of the National University of Uzbekistan, Mirzo Ulugbek, Tashkent city, Republic of Uzbekistan, Shaharchasi University, Tashkent city, Almazar District, Uzbekistan.(Email: devonhona@nuuz.uz)

S.V. Gusenina, Department of Sociology of Tambov State University, G.R. Derzhavin, Tambov city, Russian Federation(E-mail: dialog_lana@yandex.ru)

M.V. Sukhomlinova, Department of Economics and Management of Michurinsk State Agrarian University, Michurinsk city, Russian Federation(E-mail: marina27.surina @ rambler.ru)

V.I. Safyanov, Department of the Higher School of Press and Media Industry of Moscow Polytechnic University, Moscow city, Russian Federation(E-mail: vsafyanov@yandex.ru) a theoretical and practical basis to investigate the organization features of the students educating process in various educational organizations and also for different training levels in a changing multicultural environment;

the development of training courses, programs, alternative educational technologies, including the modern electronic educational resources using.

The material may be interesting to students, teachers and heads of educational institutions, and also the researchers interested in the humanization problems and the higher education quality.

Keywords: humanism; the quality of higher education; humanization of education; humanity; personality.

\section{INTRODUCTION}

The humanization of the higher education is an international problem, solved in many civilized countries and developed in international organizations. In the UNESCO Charter the education is seen as the goal for the maintaining justice, freedom and peace.

These trends characterize the need of the systemic transformations of higher education at the global level, since the current global crisis is not only political, economic, debt, but primarily sociocultural, ethical.

This topic is dedicated to the contemporary works of leading world sociologists, including Z. Bauman and L. Donskis ("Moral blindness. Loss of sensuality in a fluid modern"), J. Ritzer ("Globalization: essential moments"), W. Beck ("Twenty observations of the world in disarray ") and others. The head of Sociology Department of Moscow State Institute of International Relations, doctor of Philosophy, professor S.A. Kravchenko [10] believes that the sociocultural manifestations of the global crisis cannot be deeply understood with the help of relatively simple linear correlations in order to begin to overcome the crisis, as a first approximation, to minimize its effects and latent vulnerabilities. The humanistic turn is required which implies the integration of sociology with other scientific knowledge.

According to the authors' point, the beginning of such a humanistic turn should be connected, first of all, to a change in the qualitative approaches to studying the multi-level structure of modern education, which requires the study of the new methods and techniques' development related to the modern institutional and global transformations. 
The Russian researcher I.V. Naletova [15] proposes the complex multilevel method for studying the modern education - "metaphundamentalism".

The author identifies four levels of education: 1. the world educational space; 2 . the macro-regional traditions in higher education; 3 . the national educational systems; 4 . the higher educational institution, which provides the multifunctional analysis of the comprehensive study of higher education in the world and national culture and also in structural, systemic, institutional changes under the influence of the modern globalization processes.

A number of researchers, considering the sociophilosophical problems of education, note its humanistic nature and status as the most important sociocultural institution that has a significant impact on the development of society in its humanization meaning. These thoughts confirm the need to study the humanization phenomenon as a sociocultural phenomenon.

The humanization of higher education has a great goal the formation of the diversified personality with high physical and intellectual training, a wide range of the progressive social qualities in their interconnection professional, labor, political, philosophical, moral, aesthetic, socio-psychological, as well as a high level of the common and intellectual culture of the young people, their abilities to study and to their future activities.

The humanization of the modern students' image requires the new question's formulation about the professional culture, which should be considered not only in the narrow sense - as a complex of professional knowledge and skills, but also in the broad sense - as the totality of all social qualities of the student. The professional culture is a part of that and it's impossible to be outside or extremely limited of it [6].

So, in the Russian Federation the State Educational Standards (FSES) of the third generation, the common and professional competencies and their formation in the training of a modern specialist are defined [19].

Educational results are considered in modern Didactics as the development of the motivational combination (the value orientations, the educational interests and needs that determine the activity's motives), the cognitive (knowledge, scientific ideas about the world, the subject skills and abilities) and instrumental (mastered universal and special ways of activity) personality resources that determine the ability to solve the cognitive and practical problems that are significant for society.

Thus, "humanity" as a competence can be attributed to motivational resources that determine the activity's motives. That is why the "humanity" in the FSES is determined among the first priorities in the personal qualities.

Nevertheless, today the insufficient attention is paid to construct a model of a humane educational environment, despite the fact that humanity basically postulates the moral principle of relations between people, which is based on the caring for a person, the desire to improve his life, ensuring his needs, the free individual development, his natural inclinations and abilities.

In this regard the concepts of "humanity" is the close meaning to the concept of "personality," the quality of life and its benefit which today are the main qualitative criteria for evaluating the activities of social institutions.

\section{LITERATURE REVIEW}

The term "humanism" is associated with the name of Cicero, who defined the phenomenon as the ideology of humanity and the source of happiness, which underlies such virtues as wisdom, justice, courage, moderation.

(1) At the turn of the 20-th and 21-st centuries the theorists of humanism actualized the question of one's sociocultural status. As a result it was received an interpretation of the global phenomenon of the modern world culture, a highly significant element of the civil society in almost all democratic countries.

(2) At the present stage the priority areas of the humanistic Pedagogy are the ideology of rejection of the personality formation, but the transition to the ideology of its development, while contrasting the dominant intellectualism in educational - to the developmental training and the personality-oriented nature of education.

(3) Researchers Amonashvili Sh.A., Zagvyazinsky V.I. and Zakirova A.F. believed that in humanism the historical role of higher education is revealed as a factor in achieving harmony, the productive interaction of the future specialist and the world around him. The modern problems of humanization in education are addressed in the works of $\mathrm{E}$. Bondarevskaya. According to the author's opinion the relevance in the scientific and pedagogical activity of the theoretical provisions of the humane Pedagogy is directly related to the humanizing nature of education, filling its content with the cultural values and meanings [8].

(4) From the point of view of Gordashnikov V.A. and Osin A.Ya., the humanistic orientation in the pedagogical process can be considered as an innovative pedagogical manifestation in the reforms and educational modernization context since the ongoing changes in the pedagogical process orientation are due to the system of the new interpersonal relationships and its internal restructuring [16]. The main point of the humanistic concept is the recognition of the individual dignity, his rights and election's freedom for the realization and further development of his abilities, and also the creation of appropriate favorable learning conditions.

The authors of this work agree with the opinion of the head of the Department of Education Philosophy from Moscow State University named after M.V. Lomonosov, Bryzgalina E.V. [2], which emphasizes that today "... the essence of the educational process is the achievement of a focused transformation of social experience into a personal experience. But at the level of the secondary and higher schools there is a problem of assessing the level of educational humanization and the methods' problem to assessing the formation humanity as a person's competence degree." 
It is necessary to explain the objective reasons and difficulties that determine the logic and the need to use precisely sociological methods and techniques, which require reliable quantitative and qualitative measurement in a given research field. They are related to the role of mentality in the social behavior of individuals and the engagement of modern youth media, which in modern conditions perform a number of propaganda functions that compensate for the sharply weakened ideological Soviet ethical clichés and stereotypes.

Almost all large-scale events in the cultural, political and social spheres in the different world countries life demonstrate the importance of ideologies and their more skillful (using modern NLP techniques) their introduction into the mass consciousness, especially these processes are relevant in the youth environment. Nowadays the possibilities of social technologies are extremely great, but often the lack of a tradition of socio-technological culture leads to a change the anthropological personality image, information and technological absorption of the personality, when the culture becomes a system of subtle coercions that regulates the social processes. In this sense, the sociological methods and research procedures are the most evidencebased.

\section{MATERIALS AND METHODS \& RESULTS}

The main conclusions reliability of the study is ensured by the sociological methods and procedures universality; consistency and completeness of the comprehensive analysis to the study subject; consistency and adequacy of the methods' analysis to the study objectives.

According to the study purpose, the authors formulated the hypothesis about the high quality of the modern higher education and the achieving effectiveness of the personal learning outcomes developed and proposed by the Federal State Educational Standard. The empirical sociological study's program "Humanity as the competence of the university graduate" was compiled and in 2018 - there was a written survey among the universities' graduate students in Tambov city and in Tambov region (Tambov State Technical University, Tambov State University named after G.R. Derzhavin, Tambov State Pedagogical Institute named after S.V. Rakhmaninov, Michurinsky State Agrarian University), $\mathrm{N}=280$, in which $31 \%$ are male and $69 \%$ female, the average age is 20 years.

The quota selection was used, the survey was conducted in March 2018 during one stage. When processing the data the SPSS software package was used, ver. 21.0 for WINDOWS.

A "social portrait" can be considered as a holistic methodology that allows revealing the specific features of the social essence of the study's object, which is the result of its self-expression and includes, firstly, the systematic characteristic of all its components, and secondly, the social processes totality and relationships, associated with it. For modern Sociology the presentation of the result of the object study through "a social portrait" is very relevant. This" social portrait" gives the most complete picture of the phenomenon being studied: social characteristics can be supplemented by aspects of the associative series that are important for a particular study, expressed through images of the phenomenon being studied.

The authors formed a relatively closed circle of the scientifically correct sociological parameters, characteristics, descriptors and indicators in accordance with the Federal State Educational Standard, which allows them to be distinguished using the "social portrait" methodology and to characterize the level of conditional competence "humanity of individuals" formed by Tambov universities graduates on a universal scale of competency formation, approved by "high" - "good" - "satisfactory. At the same time, we emphasize that the formation of competence is considered by the authors of the study as a criterion for assessing not personality, but the effectiveness and quality of modern higher education.

To the authors, this aspect seems to be as important a component of the transition to a new university model as the commercialization of knowledge, online education, and distance learning. From the point of the authors view, the transition to the so-called model of the "third generation university" involves not only the development of technology, the phenomenon of artificial intelligence (Watson computer), the screening of inefficient universities, but also a new turn to the Personality.

The authors formed a relatively closed circle of the scientifically correct sociological parameters, characteristics, descriptors and indicators in accordance with the Federal State Educational Standard, which allows them to be distinguished using the "social portrait" methodology and to characterize the level of conditional competence "humanity of individuals" formed by Tambov universities graduates on a universal scale of competency formation, approved by "high" - "good" - "satisfactory. At the same time, we emphasize that the formation of competence is considered by the authors of the study as a criterion for assessing not personality, but the effectiveness and quality of modern higher education.

To the authors, this aspect seems to be as important a component of the transition to a new university model as the commercialization of knowledge, online education, and distance learning. From the point of the authors view, the transition to the so-called model of the "third generation university" involves not only the development of technology, the phenomenon of artificial intelligence (Watson computer), the screening of inefficient universities, but also a new turn to the Personality.

\section{RESEARCH RESULTS}

To evaluate the experimental data all results, that obtained according to the "social portrait" method, were divided into five semantic units, in accordance with the requirements of the Federal State Educational Standard:

- civil position and also traditional, national and universal humanistic and democratic values;

- $\quad$ service to the Fatherland and its protection;

- $\quad$ attitude to physical and psychological health; 
- the implementation of own life's plans and attitude to the profession.

Unit 1. Civil position and also traditional, national and universal humanistic and democratic values

The respondents should choose no more than three characteristics form the listed. Since the choice implied several answers, it was very clear that our survey revealed the spiritual priorities of the modern students; those results are shown in the Table 1.

\section{Table 1. Distribution of the respondents' answers to} the question

"The most positive personality traits from the university graduates' points of view", $\%$

\begin{tabular}{|l|c|}
\hline \multicolumn{1}{|c|}{ personality traits: } & $\%$ \\
\hline decency & 96 \\
\hline kindness & 95 \\
\hline responsibility & 92 \\
\hline friendliness & 85 \\
\hline veracity & 22 \\
\hline perseverance & 12 \\
\hline
\end{tabular}

According to the results of the survey, the young people call: decency, kindness and responsibility as the main positive person qualities (spiritual priorities). "Good" traditionally belongs to the most important categories of ethics and morality, it expresses the most common human interests, aspirations, wishes and hopes. It is kindness, in many respects, that forms the basis of Slavic humanity, Russian morality.

It is noteworthy that the criterion of "decency" came first (96\%), which shows, apparently, not an existing, but a proper state of public consciousness, the spiritual society life as a whole.

A person's spiritual values testify to his highest level of development, his personal maturity, they help to break out of the isolation environment limited only by material needs. It is important to note that spiritual values motivate a person to commit certain acts that are radically different from ordinary, mundane ones. That is why they themselves are an indicator of the individual humanity, as well as the moral criterion of "measuring the humanism degree."

The very anti-humanist social practice, numerous Internet notes and television programs telling about the defrauded investors, interest holders, residents of apartment buildings, patients, bank customers, and so on, make young people think about the possible protection of themselves and their loved ones, the need to master certain legal, general cultural, communicative competences, to acquire a sufficient level of knowledge that allows you to defend your guarantees, rights, dignity, opinion. Therefore, "decency", "fidelity to the spoken word", "responsibility" are so highly valued in man today. The criterion of "responsibility" was cast by $92 \%$ of the graduates.

A fourth part of the respondents note "truthfulness" (22\%). According to the Russian philosopher N. Berdyaev, "the Russian soul burns down in a fiery search for truth, absolute, Divine truth ... and its torment does not know how to quench" [1, P.22]. "Wealth", "determination", "thrift" also did not become priority qualities that determine the life of young people in modern Russia.

In turn, graduates called "irresponsibility", "egoism", and "rudeness" as the most negative personality traits. Note, that "mercantile", "greed" and "craftiness and deceitfulness" did not take root in Russia as spiritual priorities, despite the fact that such qualities are characteristic of financially successful careerists. It was not without reason that Russian epics (antiquities) and annals, proverbs and sayings constantly emphasized the anger of the invaders, craftiness and deceitfulness, coupled with cruelty, a craving for violence, which served as the basis for mentioning them exclusively as "filthy." The distribution of respondents' answers is presented in the Table 2.

Table 2. Distribution of the respondents' opinions to the question

"The most negative personality traits from the university graduates' points of view", $\%$

\begin{tabular}{|l|c|}
\hline \multicolumn{1}{|c|}{ personality traits: } & $\%$ \\
\hline irresponsibility & 93 \\
\hline selfishness & 87 \\
\hline rudeness & 83 \\
\hline commercialism & 80 \\
\hline greed & 29 \\
\hline Craftiness and deceitfulness & 19 \\
\hline
\end{tabular}

The distribution of respondents' answers to the question "Highlight the highest priority values for you" showed that the followings became: family, health, love, friends (Table 3 ). From the proposed list of values, the students were asked to rank all the values, putting at the first place those that are most important for them, and give the last places to those that are practically irrelevant.

Table 3. Distribution of the respondents' answers to the question

"Highlight the highest priority values for you", \%

\begin{tabular}{|l|c|}
\hline \multicolumn{1}{|c|}{ priority values: } & $\%$ \\
\hline family & 98,2 \\
\hline health & 97 \\
\hline love & 97 \\
\hline friends & 90 \\
\hline travel & 25 \\
\hline hobbies, interests, creativity & 12 \\
\hline position in the society & 10 \\
\hline
\end{tabular}

Thus, the humanistic potential of the spiritual priorities of Russian youth, as our survey showed, is evident. However, like the fact that, despite all the shocks that have befallen the country, the national character of the Russians has not changed.

It must be emphasized that "preserving one's own dignity" is recognized by the university graduates today as a rather significant social topic. $85.7 \%(51.1 \%+34.6 \%)$ of the young respondents acknowledge the relevance of the issue, which is evidence of the ability of yesterday's 
students to distinguish among the list of social problems the most important (related to the spiritual life of individuals and societies) that form, ultimately, the social well-being and public mood.

The fact that an individual finds himself in a difficult life situation does not mean that a person is ready for humiliation and that each person needs a special, careful attitude, since the person a priori has the right to maintain self-esteem and his status quo - this is what the results of sociological evidence show us the survey of university graduates. The distribution of respondents' answers is presented at the Figure 1.

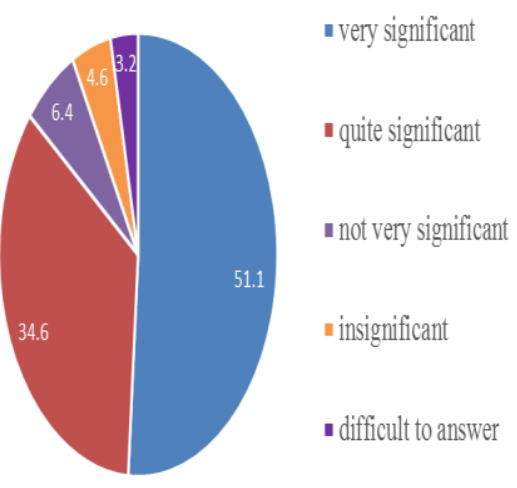

\section{Figure 1. Distribution of the respondents' answers to the question}

"Is it true that the issue of maintaining self-esteem is quite significant today?"

The following two questions were asked as a test by the universities graduates, their goal was to clarify the level of students' legal culture and the formed humanistic competencies related to the observance of personal rights and freedoms. The graduates expressed a practically unanimous opinion that they fully understand their civil rights and obligations (Table 4), despite the fact that a fourth part of them, at least once, violated the law rule or the law (Table 5).

However, the last circumstance apparently has a mental address, the academician of the Russian Academy of Sciences D.S. Likhachev emphasized that "The Russian culture is European in type, because it has always been in its deepest foundation devoted to the idea of personal freedom" [12]. Recognizing the priority of observing social norms and the law, however, sometimes a Russian person leads to liberation from conventions and rules.

\section{Table 4. Distribution of the respondents' answers to} the question

"Do you understand your constitutional rights and obligations?", \%

\begin{tabular}{|l|c|}
\hline \multicolumn{1}{|c|}{ Answers: } & $\%$ \\
\hline Yes, I clearly understand & 69 \\
\hline Rather yes & 14 \\
\hline No, I don't understand at all & 12 \\
\hline Rather no & 5 \\
\hline Difficult to answer & 0 \\
\hline total & 100,0 \\
\hline
\end{tabular}

Table 5. Distribution of respondents' answers to the question

"Have you violated the law and civil order? ," \%

\begin{tabular}{|l|c|}
\hline \multicolumn{1}{|c|}{ Answers: } & $\%$ \\
\hline Yes & 23 \\
\hline No & 77 \\
\hline total & 100,0 \\
\hline
\end{tabular}

But to the greatest degree, the humanistic potential of youth consciousness is manifested in the formulation and articulation of dreams. Here, in the best refined form, the priorities of the national culture acquired in the process of socialization are revealed, which, in turn, allows the formation of both regulatory and civil orders' conditions for identification. It is ethnic culture that maintains the stability of traditions, effectively correlates identification theory with specific actions, coordinates various types of identification the society potential [14, P. 52].

The Russian culture has its brightest features that make up its original identity, which manifests itself even in the context of cultural universals. Originality is understood as a feature, uniqueness, as well as independence, which implies the expression of an ethnic essence not through imitation and copying mechanisms, but through a substantial and constant manifestation of some components of the cultural heritage, which can be described as the "core of culture" and implies self-sufficiency.

Our survey showed that Russian universities graduates do not dream about money, even not about a career, although they would like to find a good job $(22.5 \%)$ in order to live with dignity, but: about world peace $(32 \%)$, so that everyone is healthy $(25 \%)$, about creating a family $(16 \%)$. At the same time, the graduates see their life quite realistically and don't trust the media too much (Table 6, Figure 2).

Table 6. Distribution of the respondents' answers to the question

"What are you dreaming about?" , \%

\begin{tabular}{|l|c|}
\hline \multicolumn{1}{|c|}{ What are you dreaming about? } & \% \\
\hline about world peace & 32 \\
\hline that everyone should be healthy & 25 \\
\hline find a good job & 22,5 \\
\hline create a family & 16 \\
\hline become famous & 3 \\
\hline $\begin{array}{l}\text { other (live on Mars, create a "perpetual } \\
\text { motion machine", prolong youth or life } \\
\text { etc.) }\end{array}$ & 1,5 \\
\hline total & 100,0 \\
\hline
\end{tabular}




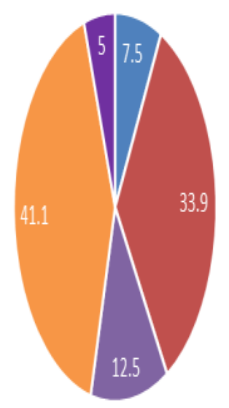

rpositively

- negatively

Figure 2. Distribution of the respondents' answers to the question

"Do you trust the modern media?", \%

\section{Unit 2. Service to the Fatherland and its protection}

Traditionally, a Russian person holds in his soul the image of the Motherland, acquiring it in the socialization process through the common values of his native ethno culture. Humanism in this sense becomes the sociocultural foundation's key in the spiritual and social life of a mature person, reflected in the sanctity of love for the Fatherland (the land of ancestors) and sacrifice in relation to the homeland (and therefore to people), which correspond to the collective consciousness of the Russians. We asked the graduates a direct question: "How much do you personally feel like a patriot of your country?" An analysis of the answers showed that $72 \%$ of the university graduates feel like patriots, and $92.5 \%$ are ready, in case of danger, to defend their homeland.

Taking "service to the Fatherland and its defense" as one of the indicators of measuring the conditional competence "a person humanity" formation, it would be argued that according to this criterion it can be assessed as "high" (according to the universal scale of formation of competencies approved by the Federal State Educational Standard). The distribution of the respondents' answers is presented in the Table 7, Figure 3, Figure 4.

Table 7. Distribution of the respondents' answers to the question

"How do you personally feel that you are a patriot of your country?", \%

\begin{tabular}{|l|c|}
\hline \multicolumn{1}{|c|}{ answers } & $\%$ \\
\hline yes, I feel & 58 \\
\hline rather yes & 14 \\
\hline no, I don't feel & 4 \\
\hline I probably do not feel & 12 \\
\hline I find it difficult to answer & 12 \\
\hline total & 100,0 \\
\hline
\end{tabular}

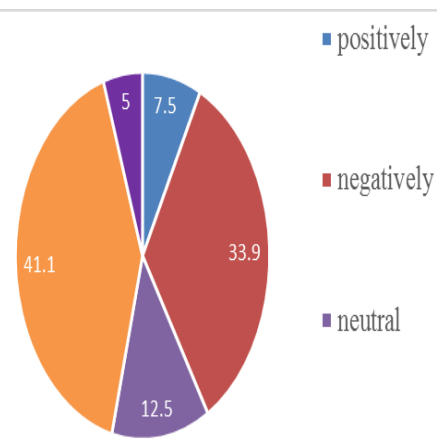

Figure 3. Distribution of the respondents to the question

"Do you agree with the statement "Where it is good, there is the homeland?", \%

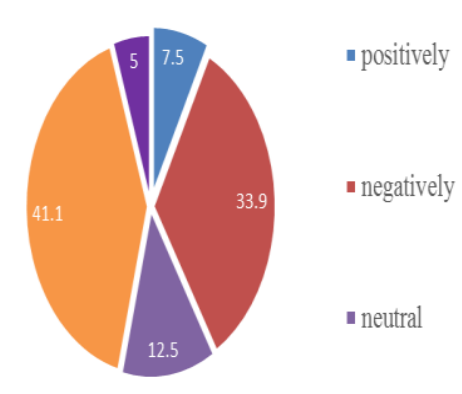

Figure 4. Distribution of the respondents to the question

"Are you ready to defence your Fatherland in the danger case? ", $\%$

The paradox of the Russian situation is that, without an ideological goal, the Russians (according to the sociological monitoring results) even today demonstrate an increase in civic consciousness in response to the aggravation of the difficult socio-economical situation. Life guidelines traditional for the Russian residents serve as a kind of moral and psychological protection, spiritual compensation for the deficit of life justice and material wealth [5, P. 362-363].

As a comparative analysis, we also present the data of the questionnaire survey "The University students about patriotism and tolerance" (the survey conducted in Tashkent city in 2018, $\mathrm{N}=582$ ). A sociological study covered the respondents studying at the National University of Uzbekistan named after Mirzo Ulugbek at the 1-4 grades faculties of "Social sciences", "Economics", "Biology and Chemistry", "Geology and Geography", "Journalism", and "Mathematics".

The analysis revealed that the main criteria for patriotism among young people are: statehood, the idea of Uzbekistan as a common home (97.8\%), "faith, language, cultural identity" (47.5\%), ethnic solidarity, historical and cultural affiliation to their nation $(54.3 \%)$, creating a special picture of the world based on their native language. Note, that the number of respondents who do not know the state language is only $2.3 \%$. 
It is interesting that the students of Uzbekistan translate the understanding of universal culture into ethnic and traditional, in which customs are passed down from one generation to the next one $(63 \%)$

When describing their native culture, students noted such features: the organic interaction with a nature $(72.4 \%)$, focus on identity and cultural identity $(80.8 \%)$ and preservation of an extended family (93.2\%), while native culture does not feel disorder from the world $(26.4 \%)$.

The survey showed that the spiritual life of young people in Uzbekistan is stereotyped in everyday practice, automated, based on the laws of their ancestors and motivated by the actions in accordance with the traditional culture $(97.3 \%)$. Despite this, realizing the indifference towards the image of the Motherland (15\%), modern youth is switching to a multifunctional behavioural choice, which shows the positive dynamics' balance of the pendulum migration in Uzbekistan. A prerequisite for social life, respondents indicate the following to the images and the models that were originally recorded in national myths $(33.8 \%)$ in the centre of attention - the sacred images that have a syncretise, undivided character.

Thus, the imperative formulated by the writer R. Kipling, "The West is the West, the East is the East, and they will never converge" is highly controversial, since such a thesis is not at all relevant to the image of the Motherland. The spiritual national heritage is an integral part of both personal development and the guarantor of the historical path of each nation. In this regard, it seems particularly relevant to comprehend a whole range of problems related to the recognition of the importance of the image of the Motherland and the degree of its sacredness, the study of the mechanisms of its formation or reconstruction, the analysis of the system of patriotic education, the identification of goals, means and effective methods of working with young people at the present stage. In this sense, a special place here belongs to social science disciplines, which retain their humanistic potential at any time and in any country.

\section{Unit 3. Attitude to the physical and psychological health}

The assertion that a healthy nation is a sign of a strong state is indisputable, so improving and maintaining health today is a priority for the state and every conscious citizen. Currently there is a necessary need for the implementation of state-wide preventive programs aimed both at combating risk factors, such as overweight, smoking, alcohol, and at early detection and adequate treatment of preventable diseases.

A series of questions in this Unit is devoted to revealing the opinions of university graduates regarding their attitude to their own and others' health, which, in our opinion, is an indicator of the formed conditional competence "humanity". The survey data is very revealing. Less than half respondents $(44.6 \%)$ believe that health is the most important thing in life, $31.1 \%$ of respondents believe that this thesis is only partially true, and $19.3 \%$ of university graduates believe that health is not at all the most main (!), the data obtained are presented in Figure 5.

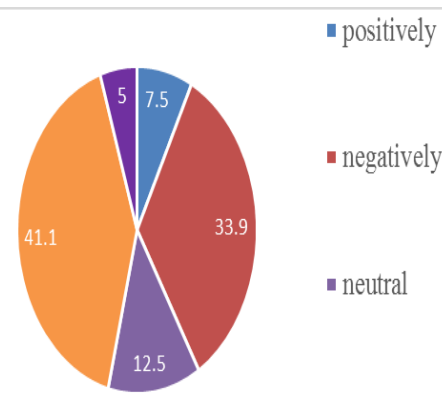

Figure 5. Distribution of the respondents' answers to the question

"Do you agree that health is the most important thing in life?", \%

A similar picture can be seen in the case of the need to provide first aid to yourself or to the person who needs it. Despite the fact that $64 \%$ of the respondents generally expressed their readiness to provide such assistance, however, $34 \%$ of the survey participants admitted that they could not provide it ( Table 8).

Taking the "attitude to physical and psychological health" as one of the indicators of measuring the formation of conditional competence "humanity of a person", it can be argued that according to this criterion it can be assessed as "satisfactory" (according to the universal scale of formation of competencies approved by the Federal State Educational Standard).

Table 8. Distribution of the respondents' answers to the question

"Can you provide first aid to yourself or to the person who needs it? , \%"

\begin{tabular}{|l|c|}
\hline \multicolumn{1}{|c|}{ answers } & $\%$ \\
\hline yes, I can & 34 \\
\hline rather yes, but how come & 30 \\
\hline no & 16 \\
\hline probably not & 18 \\
\hline $\begin{array}{l}\text { I don't know yet (I find it difficult to } \\
\text { answer) }\end{array}$ & 2 \\
\hline total & 100,0 \\
\hline
\end{tabular}

Unit 4. Realization of the own life plans and attitude to professional activities

The problems of the higher education's humanization are also revealed in the context of young people's ideas about the implementation of their own life plans and their relationship to professional activities. $58 \%$ clearly understand what they will do after their graduation, $45.4 \%$ are satisfied with their profession, and yet $28.6 \%$ of the respondents are at a crossroads (Table 9, Figure 6). Note, that $21 \%$ gave a negative answer to the question "Do you have clear ideas on the implementation of your own life plans?" This is a very alarming indicator, as well as the presence of $20 \%$ who are at a loss to give a concrete answer to this question (Figure 6). 
Apparently, this position is related to the situation on the labour market, because today a young specialist who does not have work experience cannot always find a use for himself, sometimes he is forced to work outside his profession.

Nevertheless, the distribution of the respondents' answers, presented in the Figure 7, shows that today's graduates want, hope and are confident that they will be able to work in their specialty, which testifies to their professional culture, formed in the university, their love for the profession, and that the choice of this profession was not accidental.

Table 9. Distribution of the respondents' answers to the question

"Do you have clear ideas on the implementation of your own life plans?"

\begin{tabular}{|l|c|}
\hline \multicolumn{1}{|c|}{ answers } & $\%$ \\
\hline yes & 36 \\
\hline rather yes, but how come & 23 \\
\hline $\begin{array}{l}\text { I don't know yet (I find it difficult to } \\
\text { answer) }\end{array}$ & 20 \\
\hline rather no & 12 \\
\hline definitely not & 9 \\
\hline total & 100,0 \\
\hline
\end{tabular}

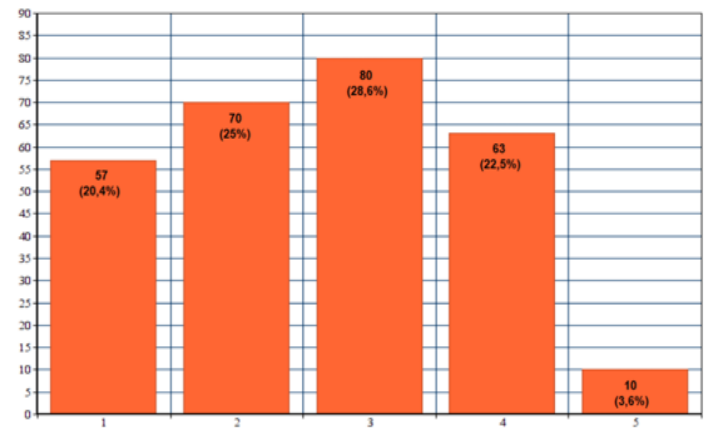

Figure 6. Distribution of the respondents' answers to the question

"Are you satisfied with the profession received at the University?" (Place your answer on a 5-point scale, where 1 is very satisfied, 5 is not satisfied)"

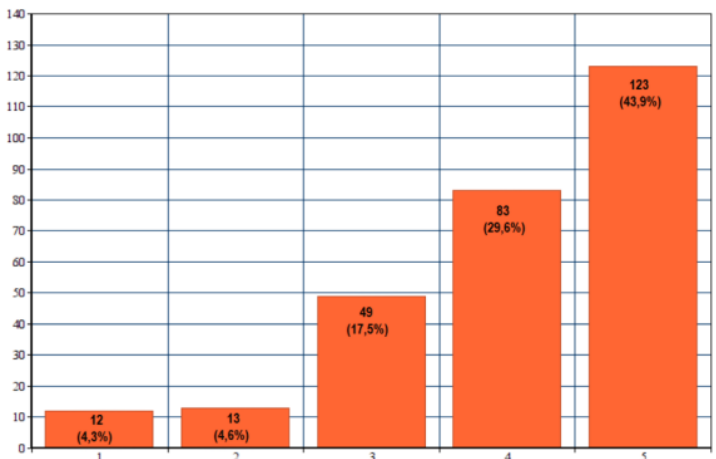

Figure 7. Distribution of the respondents' answers to the question "Evaluate and select on a 5-point scale your assessment regarding your future work in the specialty received at the University (where 0 - I will not work; 1most likely I won't; 2- how will the circumstances happen; 3- I am sure that I will, but I want to work in my specialty; 4 - I would like to work in my specialty; 5 I plan (I will) work in my specialty) "
Taking as one of the indicators of measuring the formation of conditional competence "a person humanity" clear ideas of students about the implementation of their own life plans and their attitude to professional activity, it can be argued that according to this criterion the level of the competence formation can be assessed as "good" (according to the universal scale of formation of competencies).

\section{Unit 5. Acceptance of traditional values of family life}

This block considers the opinions of respondents who participated in the survey regarding the role of the family and traditional family values.

Note, that according to this criterion, the level of competency formation can be assessed as "good" (according to the universal competency formation scale approved by the Federal State Educational Standard), since $89 \%$ of the Tambov university's graduates plan to have children, $75 \%$ negatively relate to homosexual families, $50.7 \%$ of students graduates expressed a negative attitude towards the child free movement, however, $17.8 \%$ of respondents who are positive about the movement and $31.4 \%$ of those who are negatively neutral regarding children are seriously worried. The data are presented in the Table 10, Figure 8, Figure 9.

Table 10. Distribution of respondents' answers to the question

"Do you plan to have children in the future?", \%

\begin{tabular}{|l|c|}
\hline \multicolumn{1}{|c|}{ answers } & $\%$ \\
\hline yes, I plan & 89 \\
\hline $\begin{array}{l}\text { I'm rather planning, but how will it come } \\
\text { out }\end{array}$ & 6 \\
\hline $\begin{array}{l}\text { I don't know yet (I find it difficult to } \\
\text { answer) }\end{array}$ & 3 \\
\hline rather no & 1 \\
\hline definitely not & 100,0 \\
\hline total & \\
\hline
\end{tabular}

It is noteworthy that only $49 \%$ of the graduates responded positively regarding plans to start a family, as if $9 \%$ of the respondents were not going to create a family, the rest had not yet decided (Table 11). In this sense, it becomes clear that the "family" as the highest priority value indicated in the survey by graduates (Unit 1, Table 3) implies an existing parental family or extended family, including grandparents, other close relatives, but not creating their own family. 


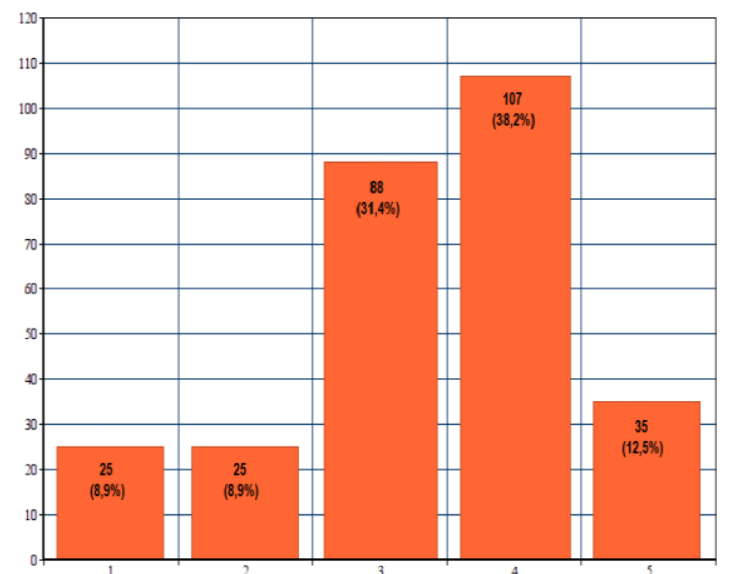

Figure 8. Distribution of respondents' answers to the question "How do you feel about the "Childfree" 1 is a very good attitude, 5 is a very bad attitude, \%"

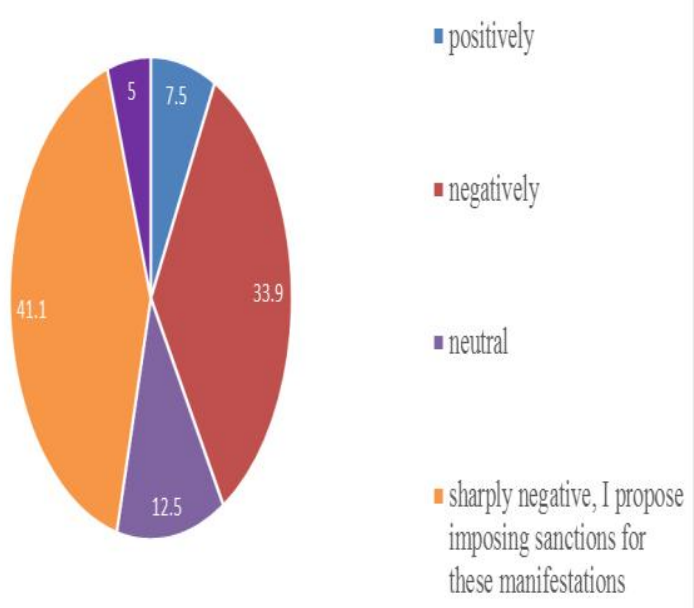

Figure 9. Distribution of the respondents' answers to the question

"How do you feel about homosexual families?", \%

Table 11. Distribution of the respondents' answers to the question: "Are you going to start a family in the next five years?"

\begin{tabular}{|l|c|}
\hline \multicolumn{1}{|c|}{ answers } & $\%$ \\
\hline yes, I plan & 49 \\
\hline I'm rather planning, but how will & 28 \\
\hline $\begin{array}{l}\text { I don't know yet (I find it difficult to } \\
\text { answer) }\end{array}$ & 13 \\
\hline rather no & 1 \\
\hline definitely not & 9 \\
\hline total & 100,0 \\
\hline
\end{tabular}

\section{DISCUSSION AND CONCLUSIONS}

The analysis of the experimental work data revealed a good level of the formed conditional competence "a person humanity" among the respondents-graduates of universities in Tambov region in accordance with the requirements of the Federal State Educational Standard for personal educational results. The basis of this assessment was the empirical data obtained in the process of a sociological survey on five main parameters: movement? (Place your answer on a 5-point scale, where

- $\quad$ civic position, traditional, national and universal humanistic and democratic values - a high level;

- $\quad$ service to the Fatherland and its protection - a high level;

- $\quad$ attitude to physical and psychological health - a satisfactory level;

- 4) the implementation of their own life plans and attitude to professional activities - a good level;

- 5) the adoption of traditional values of family life is a good level.

The results and conclusions of the empirical author's research can serve as a theoretical and practical basis for studying the features of the educating process' organization of the students at the various educational organizations and training levels, in a changing multicultural environment, the development of training courses, programs, alternative educational technologies, using the modern electronic educational resources. The material may be interesting for the teachers, students and heads of educational institutions, researchers interested in the problems of humanization and the quality of higher education.

We see further scientific studies of this problem in studying the issues of determining the substantive minimum and requirements for the results of the additional educational competencies' development, corresponding to various types of activities; in the field of spiritual and moral education and upbringing, improvement of innovative methods at the educational process, the high-quality training of humanities specialists in accordance with the demands of the labor market.

\section{DISCLOSURE STATEMENT}

No potential conflict of interest was reported by the authors.

\section{REFERENCES}

1. Berdyaev N. Soul of Russia / N. Berdyaev .- M . T8RUGRAM, 2018.-140p.

2. Bryzgalina E.V. Humanization and humanitarization of education: from school to university [Electronic
[ellow resource] / E.V. Bryzgalina. - Access mode http://lib.teacher.msu.ru/pub/2303.

3. Wissema, Johan G. University of the third generation. M.: Olympus - Business, 2016 .- 432 p.

4. Gordashnikov V.A., Osin A.Ya. Education and health of students of a medical college.- M .: Academy, 2009.- 395 p.

5. 5.Gorshkov M.K. Russian society in the conditions of transformation (sociological analysis). - M.: "Russian Political Encyclopedia” (ROSSPEN), 2000. - 384 p.

6. Dobruskin M.E. Humanization as a strategy of higher education. - Journal: Philosophy and Society. Issue No. 3 (40) / 2005. [Electronic resource] / E.M. Dobruskin. Access mode https: // www. socionauki. com / journal / articles / 126657.

7. Ivanko V.Yu. Problems of humanization of vocational education [Electronic resource] / V.Yu. Ivanko.- Access mode https://nsportal.ru/npo-spo/sotsialnyenauki/library/2016/02/12. 
8. Karavanov A.A., Ustinov I.Yu. Actual problems of humanization and humanization of military engineering education // Scientific Review. Pedagogical sciences. 2016. - No. 3. - P. 57-85.

9. Kravets, A.S. Humanization and humanitarization of higher education. [Electronic resource] / A.S. Kravets // Voronezh State University. - Access mode: http://www.rciabc.vsu.ru/irex/pubs/kravets2.htm.

10. Kravchenko S.A. The formation of a complex society: for a humanist turn // Humanitarian of the South of Russia .2013. V. 0. No. 3. P. 141-146.

11. Culture as the basis of the content of education // Site of Academician RAO Novikov AM [Electronic resource]. Access mode: http: // anovikov. com / artikle / kult_osn.htm

12. Likhachev D. S. Book of worries / Articles, conversations, memories /. - M.: Publishing house "News", 1991. [Electronic resource] / D.S. Likhachev. Access mode: http://svitk.ru/004_book_book/ 16b / 3559.

13. Lopatin A.R. The formation of social maturity among schoolchildren in the context of a humanistic approach // Bulletin of Kostroma State University. ON. Nekrasov. 2013. - V. 19. - No. 4. P.7-9.

14. Marshak A.L. Cultural identity as a factor in strengthening the integrity of Russia // Humanitarian of the South of Russia. 2014. No. 4. P. 50-54.

15. Naletova I.V. Research analytics of higher education as a culture-forming constant of our time Specialty 24.00.01 Theory and history of culture: abstract of a dissertation for the degree of Doctor of Philosophy. - Tambov.-2005. $44 \mathrm{p}$.

16. Problems and prospects of spiritual and moral education of adolescents and youth in the context of the introduction of federal state education: materials of the All-Russian scientific and practical conference (March 18, 2011). - Tambov: TOGAU DPO "Tambov Regional Institute for Advanced Training of Education Workers", 2011.- 187 p.

17. Problems of modern teacher education. - Collection of scientific papers: - Yalta: RIO GPA, 2018. - Issue. 61. Part 4. - 334 p.

18. Romanyuk L.V. Humanistic pedagogy. [Electronic resource] / L.V. Romanyuk. - Access mode file: / C: / Users / user / Downloads. /pdf.

19. GEF // Official site of the National Association for the Development of Education and Science. [Electronic resource]. - Access mode: https: //fgos.ru/.

20. Chernitskaya A.L. Humanization of higher education: the nature and prospects of development: an abstract of a dissertation for the degree of candidate of Philosophical sciences: 09.00.11 / Chernitskaya Anna Leonidovna; [Place of protection: Moscow State reg. Un-t]. - Moscow, 2008 .- 23 p. 